\title{
O conceito de fenomenologia de Martin Heidegger em ser e tempo
}

\begin{abstract}
Alisson Matutino de Souza*
Resumo: O objetivo de nosso artigo é analisar o conceito de fenomenologia heideggeriano no $§ 7$ da obra Ser e Tempo. Procuramos examinar em que medida Heidegger pretende precisar a necessidade de re-pensar a questão do sentido do ser, devido à ausência de uma reposta adequada sobre o mesmo na História da Filosofia. Detivemo-nos a analisar qual o sentido da reelaboração do lema: "de volta às coisas elas-mesmas" que Heidegger trabalha em relação ao seu mestre Husserl. Propomos examinar a posição especial de Heidegger face ao problema da articulação da ontologia com a fenomenologia. E qual a inovação é acrescentada à Fenomenologia enquanto método quando Heidegger a interpreta como uma Hermenêutica da factualidade para seu projeto filosófico. Palavras-chave: Fenômeno, Logos, Fenomenologia, Ontologia e Hermenêutica.
\end{abstract}

\section{The concept of Phenomenology in Heidegger's Being and Time}

\begin{abstract}
The objective of our article is to analyze the concept of heideggerian phenomenology in $\S 7$ of the work Being and Time. We try to examine to what extent Heidegger intends to specify the necessity of re-thinking the question of the sense of being, due to the absence of an adequate answer on the same in the History of Philosophy. We were left to analyze the meaning of the re-elaboration of the motto: "back to the things themselves" that Heidegger works in relation to his master Husserl. We propose to examine Heidegger's special position on the problem of articulation of ontology with phenomenology. And what innovation is added to Phenomenology as a method when Heidegger interprets it as a Hermeneutics of factuality for his philosophical project. Keywords: Phenomenon, Logos, Phenomenology, Ontology and Hermeneutics
\end{abstract}

\section{Considerações iniciais.}

O objetivo do presente trabalho é examinar o conceito de fenomenologia que Heidegger apresenta na sua obra Ser e Tempo (Sein und Zeit). Desejamos com essa exposição mostrar como a necessidade de pensar um novo método vem ao encontro da necessidade de re-velar a questão para Heidegger fundamental da filosofia, que não é outra coisa senão a questão do sentido do ser em geral, ou mais precisamente, a interrogação sobre a unidade do sentido do ser na multiplicidade de suas acepções. A escolha do método está embasada naquilo que Heidegger detecta com relação à história da tradição metafísica. Segundo esse autor, toda história da metafísica é exatamente a história do esquecimento do ser, já que, o ser na metafísica é sempre tratado como ente. O ser é sempre objetificado e, nesse processo, imediatamente identificado como qualquer outro ente. Esta é a premissa principal de

\footnotetext{
* Mestrando em filosofia pelo Programa de Pós-graduação em Filosofia (PPGFIL) do Instituto de Filosofia (IFILO) da Universidade Federal de Uberlândia (UFU). Bacharel em filosofia pela Faculdade Católica de Uberlândia e Bacharel e Licenciado em Filosofia pela Universidade Federal de Uberlândia (UFU). Bolsista pela FAPEMIG. Email: alissonmat1@hotmail.com
} 
Heidegger em sua crítica ao esquecimento do ser pela metafísica: evitar entificar o ser. Como o próprio Heidegger nos revela: “[...] a pergunta pelo sentido do ser não só não foi concluída, não só não se formulou de modo suficiente, mas, com todo interesse pela "metafísica”, caiu no esquecimento". (2012, p. 85).

Procuramos nos deter na exposição do $\S 7$, no qual o autor trata da necessidade de pensar uma nova via de acesso à questão ontológica. Procuramos mostrar que a necessidade de pensar um novo método para ontologia se dá devido à ausência de uma reposta adequada sobre o sentido do ser na história da filosofia. Dessa maneira, enquanto identificada à ontologia, a fenomenologia será o método que fará trazer à luz o ser como sentido velado nos entes. Atentamos mais especificamente à démarche assumida por Heidegger na identificação que ele corrobora entre ontologia e fenomenologia. Para compreender o alcance dessa relação, procuramos explicitar como a fenomenologia será exposta provisoriamente, mediante as determinações do sentido das partes que a compõe: phainómenon e logos. Para tanto, nosso autor fará uma análise filológico-filosófica a partir das raízes gregas de ambos os termos.

Então, a partir das interpretações dos termos "fenômeno" e "logos", Heidegger formula em grego a expressão fenomenológica: legein tà phainomena. Uma vez que, segundo a leitura heideggeriana, legein adquire o sentido de apophainestai, então "fenomenologia" pode ser formulada como apophainestai tà phainomena: “[...] fazer ver a partir dele mesmo o que se mostra tal como ele por si mesmo se mostra". (2012, p. 119). Procuramos assim determinar que a tarefa do método fenomenológico se funda na própria necessidade de o fenômeno ser desvelado, sobretudo porque a miríade de manifestações e modos que o ser pode se dar a conhecer somente pode ser captado consubstancialmente a um instrumento que se adaptasse às múltiplas maneiras desta dadidade (gegebenheit).

Procuramos, nesse primeiro capítulo, expor a íntima conexão entre a verdade como alétheia e a noção de fenomenologia, enquanto desvelamento, como necessidade que decorre, por conseguinte, da própria exigência que o fenômeno impõe de ser desvelado. A verdade assim se manifesta em comunhão com o ser que se descobre como verdadeiro pelo fato dele já se mover de pronto e, no mais das vezes, 
no ser do ente que descobre-se como des-velador. Por fim, procuramos mostrar por que a ontologia fundamental será, portanto, uma fenomenologia hermenêutica, no sentido da interpretação do entendimento contido na existência fática do homem, bem como seus desdobramentos hermenêuticos. Desse modo, Heidegger ao fazer uso do método hermenêutico, procura elucidar que a investigação é hermenêutica na medida em que o ponto de partida para alcançar a descrição do sentido de ser enquanto tempo é o próprio entendimento do ser pré-ontológico do Dasein, o qual, por sua vez, deverá ser trazido à luz em relação a suas condições de possibilidade mediante uma adequada interpretação.

Heidegger pretende precisar a necessidade de re-pensar a questão do sentido do ser, devido à ausência de uma reposta adequada sobre o sentido do ser na História da Filosofia. Como ele mesmo afirma, "só no efetuar a destruição da tradição ontológica é que a questão-do-ser conquista sua verdadeira concretização”. (2012, p. 99). Heidegger toma o termo "ontologia" em um sentido formal e amplo. Se assim sucede com o fundamento alvo ou mesmo com o objeto que se busca indagar, o mesmo também deve se levar em conta com relação ao método. Assim ele nos alerta que "[...] fica por si mesmo interditado o caminho que consistiria em seguir a história do termo, para elucidar-lhe o método" (2012, p. 99), haja vista que o método e toda ontologia que Heidegger busca não coincidem com nenhuma disciplina filosófica até então existente. Como nos acrescenta Marlène Zarader:

\footnotetext{
Por ontologia, é preciso entender evidentemente aqui a ontologia a vir. E não as ontologias existentes, que não são jamais ordenadas ao modo de doação do ente para anunciar o ser, mas que procederam em sentido inverso: elas não são dirigidas sobre ente senão já munidas de uma certa compreensão do seu ser, elas não deixaram falar, pois, o fenômeno (MARLÈNE ZARADER, 2012, p.79) ${ }^{2}$.
}

Vemos assim que a radicalidade que Heidegger quer conquistar com sua busca pelo sentido do ser, faz com que ele não escolha aleatoriamente ou de forma gratuita seu método. O método que ele tem em vista é um método que se determine pela própria questão fundamental da Filosofia, ou seja, a questão do sentido do ser, que ficou impensada ao tomar o ente pelo ser. Assim, a antiga aporia aristotélica do ser na sua unidade em relação com seus múltiplos significados se torna a pauta das questões que precisam ser esclarecidas. Desse modo, o filosofar heideggeriano não

\footnotetext{
${ }^{2}$ As traduções dessa obra e de Jean-François Courtine são de nossa autoria.
} 
pode, ao buscar tal radicalidade, se fixar em repostas determinadas, como esse autor mesmo nos adverte:

Não se trata de satisfazer em geral às exigências da tarefa de uma disciplina já-dada, mas, ao oposto: poder-se-ia em todo caso constituir uma disciplina a partir das necessidades de-coisa de um perguntar determinado e o modode-tratamento exigido pelas "coisas elas mesmas". (HEIDEGGER, 2012, p. $101)$.

Heidegger não quer associar seu trabalho, no que tange ao seu método, com nenhuma orientação filosófica até então existente, mas apenas apreendê-la como possibilidade de se pensar o sentido do ser. Ao tomar para si o lema rumo "às coisas elas mesmas," Heidegger retoma o seu mestre Husserl, que foi o primeiro a estabelecer esse signo sobre o qual vários movimentos fenomenológicos se uniam. Segundo o próprio Husserl, "O método da crítica do conhecimento é o fenomenológico; a fenomenologia é a doutrina universal das essências [...]" (HUSSERL, 1990, p. 22). Ele formula essa fenomenologia como "ciências das essências", pensando-a em relação à redução fenomenológica, como retorno à consciência, possibilitado pela epoché (suspensão da tese naturalista). É no método de redução fenomenológica que Husserl estabelece que o objeto na sua constituição é correlato dessa consciência. Para Heidegger, nessa perspectiva de uma fenomenologia transcendental, o ser do ente é reduzido à dimensão de objeto da consciência. Chamada também de "redução eidética," justamente por ser uma fenomenologia como uma doutrina da essência do conhecimento (a priori), que, portanto, visa o "eidos" enquanto total transparência reflexiva, que reduz o ser à sua essência como correlato da consciência. Contrariamente a essa filosofia do seu mestre, Heidegger vai seguir uma via transversa a essa pura objetivação da determinação ontológica. Segundo Ernildo Stein:

[...] para ele o papel da fenomenologia consistia em se inserir nessa realidade que escapa à total autotransparência e nela manifestar aquilo que ali se ocultava à reflexão, assim como a partir de si se manifestava, isto é, ocultando-se para a realidade reflexiva. Assim Heidegger queria atingir o ser do ente, muito além das dissimulações da vida em seu acontecer concreto [...]. Para o filósofo a fenomenologia de nenhum modo pode corresponder às exigências da radicalidade husserliana de autofundar a própria facticidade na total transparência. Para ele isso é impossível. O fato de o ser-aí ser uma facticidade faz com que ele seja irredutível a uma total transparência reflexiva. Sua facticidade é a existência. (ERNILDO STEIN, 2001, p. 153).

Heidegger, dessa forma, lança mão, então, da fenomenologia herdada de seu mestre Husserl, fazendo adaptações profundas, ao dar ao método fenomenológico 
husserliano uma nova leitura e uma nova forma de aplicação. Diante do mote da tese husserliana que visava as "coisas elas mesmas", Heidegger não buscará satisfazer sua metodologia via redução fenomenológica em que, retornando à consciência, os objetos apareceriam na sua constituição como correlatos dessa consciência. Tomando como ponto de partida a factualidade da vida, a existência como essência do Dasein, ser-emo-mundo são elementos fundamentais para pensar sua crítica fenomenológica de seu mestre Husserl. Ao longo da exposição analítica deste $\S 7$ iremos trabalhar melhor a construção desta nova ontologia fenomenológica proposta por Heidegger.

Heidegger não se liga a nenhuma démarche ontológica da história da filosofia. "Com a pergunta diretora pelo sentido do ser, a investigação se põe ante a pergunta fundamental da filosofia em geral. O modo-de-tratamento dessa pergunta é o fenomenológico" (2012, p. 101). A fenomenologia, nessa acepção, tanto no seu sentido como no seu objetivo, não tem como meta vir a prescrever um "ponto-de-vista" ou uma "corrente", pois ela quer, nesse conceito prévio, significar pontualmente um "conceito-de-método". Heidegger prioriza sua posição singular de conceito-demétodo, apontando que sua proposta fenomenológica não tem como meta caracterizar os conteúdos dos objetos, como se fazia outrora, isto é, mostrando-se a quididade dos objetos de investigação, sua proposta fenomenológica apenas caracteriza, antes, o seu "como", o modo de proceder da sua filosofia. Heidegger ainda alerta que o método não é entendido fora, ou seja, exterior e com um "manejo técnico" devido a sua ligação intrínseca com o objeto que ela busca explicitar. Pois, seu respaldo e fundamento serão tão mais abrangentes se determinarem o movimento dos princípios de cada ciência. Com isso, maior será a originalidade em que esse método virá a se radicar: numa discussão com "as coisas elas mesmas". Podemos destacar que o ponto de encontro entre Heidegger e seu mestre, segundo Marlène Zarader, considerando o lema "as coisas elas-mesma" pode assim ser assinalado:

\footnotetext{
Esta máxima significava para Husserl, e significa sempre para Heidegger, de uma parte, que convêm se desembaraçar de toda teoria ou de toda préconcepção através das quais se abordaria a coisa, de outra parte, que convém voltar-se para a coisa mesma, e de se ter em conta escrupulosamente a maneira pela qual ela se dá. (MARLÈNE ZARADER, 2012, p. 79)
}

Heidegger assinala que “o termo „fenomenologia ${ }^{\text {ee }}$, exprime uma máxima que pode ser assim formulada: ,às coisas elas mesmas!” (2012, p. 101). Com esse lema impulsionador de sua ontologia fenomenológica, ele quer escapar das 
sistematizações sem fundamento, das descobertas casuais, da admissão de conceitos só aparentemente verificados, bem como das pseudo-questões que continuamente se apresentam como problemas ao longo do tempo.

\subsection{Descrição fenomenológica do conceito de fenômeno e logos.}

A fenomenologia será exposta provisoriamente por Heidegger mediante as determinações do sentido das partes que a compõem enquanto termo: phainómenon e logos. Marlène Zarader, com relação à escolha heideggeriana para explicitar seu método, nos mostra que:

Para defini-lo, poder-se-ia (dever-se-ia) referir-se à história da fenomenologia, e se reportar aos textos de seu fundador: Husserl. Ora não é assim que procede Heidegger. No lugar de se reportar à história dessa corrente, real, que foi a fenomenologia, ele se reportará à história da palavra fenomenologia, mais exatamente à composição mesma dessa palavra. O que autoriza a proceder assim? É que, a seus olhos, Husserl estabeleceu um solo. Solo com qual ele tem certamente edificado um certo edifício (aquele do idealismo transcendental), mais que pode servir de solo a todas as outras démarches, de outra maneira orientada. (MARLÈNE ZARADER, 2012, p. 80)

A escolha dessa via de abordagem operada por Heidegger não tem nada de arbitrária. Mesmo porque ele tem como meta interrogar os termos em seus sentidos originários, anteriores a todos os encobrimentos postos pela tradição. De forma aparente e exterior o nome “[...], ,fenomenologia"e está formado da mesma maneira que teologia, biologia, sociologia, nomes traduzidos como ciência de Deus, da vida, da sociedade”. (HEIDEGGER, 2012, p. 103). O conceito de fenomenologia, seguindo essa linha de compreensão seria a "ciência dos fenômenos". Como vimos, a elaboração do conceito formal de fenomenologia é remetida e preparada pela análise semântica das duas partes que a compõem, apoiando-se nas raízes etimológicas dos conceitos gregos.

Heidegger analisa primeiro o conceito de fenômeno:

A expressão grega phainómenon, à qual remonta ao termo "fenômeno, deriva do verbo phainesthai, que significa mostrar-se; phainómenon significa, portanto, o que se mostra, o se-mostrante, o manifesto. Phainesthai é, ele mesmo, uma formação média de phaino, trazer à luz do dia, pôr em claro; phaino pertence à raiz pha - como phos, a luz, o claro, isto é, aquilo em que algo pode se tornar manifesto, pode ficar visível em si mesmo. Como significação da expressão "fenômeno" deve-se, portanto, reter firmemente: o-que-se-mostra-em-si-mesmo, o manifesto. Os Phainomena, os "fenômenos" são então o conjunto do que está à luz do dia ou que pode ser posto em claro, aquilo que os gregos às vezes identificarem 
simplesmente com ta onta (o ente). Ora, o ente pode se mostrar, a partir de si mesmo, de diversos modos, cada vez segundo o modo-de-acesso a ele. (HEIDEGGER, 2012, p. 103).

Segundo Heidegger, o ente pode mostrar-se de diferentes maneiras como correlato ao modo pelo qual são abordados ou evocados. Desse modo, ele pode até mostrar-se como aquilo que ele não é. Tal modo de "mostrar-se" Heidegger denomina parecer, ou mais precisamente, "é como se..." "Aparência" (Schein), é esse o termo usado pelo autor para definir quando o ente manifesta "o que é como se". Nesse modo de se manifestar, o ente pode ocultar ou velar-se, não sendo aquilo mesmo que se dá. Heidegger ainda salienta que este binômio velamento-desvelamento, ou melhor, oque-se-mostra-em-si-mesmo, o aparente, ou a aparência do fenômeno no sentido grego estão enlaçadas pela própria raiz estrutural do conceito de fenômeno (phainómenon). Contudo, a primeira significação fundamenta a segunda. "Onde começa a propriamente nos falar a análise heideggeriana, ou a interpretação? Não na constatação desses dois sentidos, mas na afirmação que o segundo encontra seu fundamento no primeiro" (MARLÈNE ZARADER, 2012, p. 81). Assim mesmo nos revela Heidegger: "Só na medida em que algo, segundo seu sentido, pretende em geral se mostrar, isto é, ser fenômeno, é que ele pode se mostrar como algo que não é, podendo "somente aparentar ser como...”. (2012, p. 105). Nessa perspectiva, nosso autor usa o conceito "fenômeno" em sua atribuição positiva e original, ao passo que ele distingue "aparência", o "aparente" como modificação privativa do termo fenômeno.

Heidegger resume essas variações do conceito de fenômeno, salientado que o conceito de fenômeno como o-que-se-mostra-em-si-mesmo abarca uma distinção radical entre fenômeno (phänomem), aparência (Schein), aparecimento (Erscheinung), mero aparecimento (Blosse Erscheinung). O termo fenômeno precisou ser esclarecido por Heidegger, para melhor compreendê-lo em todo o seu alcance. Com isso, ao entender o fenômeno como modo privilegiado de algo vir-de-encontro, mantido nestes termos em sua real significância, ele fica livre de ser confundido com os significados que dele derivam e, sobretudo, nele encontram seu fundamento. Assim, a chave da leitura heideggeriana para se evitar toda confusão que possa brotar deste termo "fenômeno" e de toda sua polissemia é, desde o início, tomar o conceito como o-que-se-mostra-por-si-mesmo.

Heidegger pretende analisar o histórico do conceito logos, como uma das partes do termo que compõem o conceito fenomenologia, assim como ele já fizera em 
sua descrição do termo "fenômeno". A intenção de Heidegger que preside o seu trabalho de busca de solapar todo endurecimento e encobrimento desses conceitos (phainómenon e logos), visa a construção de seu método fenomenológico e as possibilidades de uma nova compreensão do método.

Assim, com essa compreensão é que o professor de Freiburg interpreta que as disputas e divergências sobre os conceitos de logos dos filósofos antigos Platão e Aristóteles muito se devem à falta de uma interpretação que revele seu significado fundamental. Como Marlène Zarader diz: "tem várias significações, cujo laço não é claro" (2012, p. 83). Disto provém toda plurivocidade que o termo traz consigo. Para Heidegger, na verdade "[...] trata-se somente de uma aparência que se mantém enquanto a interpretação não é capaz de apreender adequadamente o significadofundamental em seu conteúdo primário”. (2012, p. 113). Sendo assim, quando se traduz o termo logos por discurso como seu significado-fundamental, esse significado não apresenta a radicalidade a qual está embasada essa determinação da significação do termo. Assim, de resto, os significados tardios e secundários na verdade encobrem e dissimulam sua originalidade. Daí que toda gama de interpretações múltiplas e arbitrárias da história do sentido de logos mascaram de tal maneira o sentido de discurso, que "logos é „traduzido", isto é, sempre interpretado como razão, juízo, conceito, definição, fundamento, relação”. (2012, p. 113).

O significado de logos destacado por Heidegger é "[...] tornar manifesto aquilo de que „se discorre ${ }^{\text {ee }}$ no discurso” (2012, p. 113). Esse termo, exposto dessa forma, remonta a Aristóteles, por justamente ter se tornado a partir dele um termo que tem o sentido num caráter declarativo ou revelativo.

\footnotetext{
Aristóteles explicitou mais nitidamente essa função do discurso como apophainesthai. O logos faz ver algo (phainesthai), a saber, aquilo sobre o que se discorre e faz ver $a$ quem discorre (voz média) e aos que discorrem uns com os outros. O discurso "faz ver" apo... a partir daquilo mesmo de que discorre. No discurso (apophansis), na medida em que é autêntico, o dito no discurso deve ser extraído daquilo sobre o que se discorre, de tal maneira que a comunicação por discurso torne manifesto o dito e, assim, acessível ao outro aquilo sobre o que se discorre. Essa é a estrutura do logos como apophansis. (HEIDEGGER, 2012, p. 113-115).
}

A realização concreta do discurso acontece na linguagem, uma vez que "[...] o discorrer (fazer-ver) tem o caráter do falar, da proferição vocal com palavras". (2012, p. 115). Desse modo, sendo a linguagem este veículo por "onde" a fala é intensificada e comunicada, o logos se torna mais precisamente "proferição vocal em 
que cada vez algo é visto.” (2012, p. 115). Além dessa notificação vocal, em que alguma coisa é dada a ver, ou mais precisamente, é significada no discurso como manifestação daquilo que se fala. Segundo Heidegger, logos tem uma função estrutural de synthesis, justamente porque a função do logos como apophansis “[...] consiste em fazer algo mostrando [...]" (2012, p. 115). Concebendo logos como síntese, não quer Heidegger dizer que por isso exista uma adequação instituída pela verdade numa relação de correspondência de algo interno com que existe de físico lá fora. Isto é, esse autor não quer pensar o logos sobre os moldes da definição clássica de verdade: como adequação do intelecto e da res.

A definição que o autor apresenta da "verdade" em relação ao logos, enquanto fazer-ver como manifestação daquilo de que se fala, não é posta como o "lugar" originário da verdade. "O logos não é o lugar primordial da verdade porque é um modo determinado de fazer ver" (ERNILDO STEIN, 2001, p. 166). Heidegger quer buscar a relação logos e linguagem anterior ao ponto em que se chegou a acreditar na relação necessária entre o pensamento e o modo lógico do juízo como forma unicamente rigorosa para se chegar à verdade. Aprofundando essa crítica, Heidegger defende que logos, no seu sentido derivado e tardio, não é constituinte da verdade do ser, sobretudo porque ela não é construção de um juízo, mas sim desvelamento daquilo que se oculta nos entes.

Heidegger nos alerta com relação ao conceito grego de verdade: não “[...] se define a verdade, do modo como hoje se tornou de todo usual, como algo que compete ,propriamente a juízo [...]” (2012, p. 117). Desse modo, certo é que, para os gregos, a verdade está numa dimensão mais originária que o logos. Isto é, ela se encontra na aisthesis, pois é "onde" ocorre a apreensão sensível de alguma coisa. Heidegger quer nos mostrar a relação direta que há entre a aisthesis e o contato com mundo. Ou seja, não há hiatos ou algo que se justaponha nesse modo sentiente. Por isso, nessa relação, a aisthesis visa fundamentalmente o que é acessível por ela e para ela. Assim, ao vislumbrar um pôr do sol ou ouvir um som da cítara, percebemos que o ver descobre cores, o ouvir descobre sons, de modo que é sempre verdadeiro. Não há, nesse ato de perceber encobrimento, pois o que se dá é verdadeiro. "É o puro noein, o perceber simples que vê as mais simples determinações-de-ser do ente como tal. Esse noein nunca pode encobrir, nunca pode ser falso, pode permanecer no máximo um não-perceber, agnoein insuficiente para um acesso simples e adequado". (2012, p. 117). 


\title{
1.2 A articulação conceitual entre Ontologia e Fenomenologia: descrição do conceito prévio de fenomenologia
}

Heidegger, depois de ter descrito os termos que compõem o termo fenomenologia a partir da semântica grega, pretende, na parte $C$ do $\S 7$, fixar o fio condutor de todo indagar filosófico, compreender de onde ele brota e para onde ele deve se desenvolver. Como veremos nessa relação entre os termos, o método chega a sua explicitação como resultado da analítica existencial, de modo que a unidade interna entre objeto e método se torna intrínseca dentro da dinâmica e sistemática de Ser e Tempo. Para melhor compreendermos esse conceito prévio de fenomenologia e a íntima ligação entre os seus termos, descrevemos como Heidegger apresenta o conceito provisório de fenomenologia:

\begin{abstract}
A expressão "fenomenologia" pode ser formulada em grego: legein ta phainomena; legein significa, porém, apophainesthai. Fenomenologia diz, então, apophainesthai ta phainomena, fazer ver a partir dele mesmo o que se mostra tal como ele por si mesmo se mostra. Esse é o sentido formal da pesquisa que a si mesma se denomina fenomenologia. Mas assim, nada mais se exprime do que a máxima já formulada: "às coisas elas mesmas!". (HEIDEGGER, 2012, p. 119).
\end{abstract}

Heidegger, ao resumir a fórmula do seu método no lema de seu mestre Husserl, não quer com isso voltar ao paradigma da subjetividade, marcado pelas teorias da consciência e da representação. Já que, para Husserl "a tarefa da fenomenologia é designada então claramente: pôr em luz a subjetividade da consciência em sua incondicionalidade e sua inabalável certeza a título de presença-asi.” (COURTINE, 1990, p. 189). Como se pode ver, a máxima husserliana clama por um novo sentido. Uma vez que "as coisas" têm de passar por um reconhecimento de sua constituição, embasada na reiificação da relação sujeito-objeto da teoria cartesiana. Assim, o conceito de "coisas" em Husserl traz os pré-conceitos da teoria da consciência moderna instituída por Descartes. Segundo Courtine, "a problemática da epoché e da redução é, no entanto, abordada tematicamente a favor do exame da determinação husserliana do campo (Feld) próprio da pesquisa fenomenológica: a região da pura consciência e seus correlatos, a região do puro Eu”. (1990, p. 221). Neste sentido, “a coisa” está especialmente associada à noção de objeto de Descartes, baseado na teoria do objeto formulada nas Regulae. 
Aprofundando essa crítica a Husserl, podemos constatar que a redução fenomenológica pensada por Heidegger visa uma região inteiramente inexplorada. Sobretudo porque ele não pode nesse movimento regressivo repetir a sedimentação da tradição e, com isso, toda tendência para encobrimento do ser e a ocultação do seu sentido. O lema impulsionador para voltar "às coisas elas mesmas" quer reconduzir o olhar do ente para o ser, pois o Dasein é o ente assinalado para pensar toda analítica enquanto ser- no-mundo. Marlène Zarader acentua que: "o que é, pois, radicalmente novo em Heidegger, e o que dá toda uma nova orientação à fenomenologia, é devido a diferença que ele traça entre ente e ser" (2012, p. 86).

Tais fenômenos se constituem essencialmente nesse binômio velamentodesvelamento, que levou toda a tradição a acreditar que, ao explicitar o ente, acreditavam que estavam explicitando o ser e seu sentido. Dentro dessa emblemática necessidade de expor seu método no sentido fenomenológico, derivado do sentido formal, Heidegger nos aponta que o fenômeno, em seu sentido privilegiado pode assim ser descrito:

É manifesto que se trata do que precisamente não se mostra de pronto e, no mais das vezes, do que permanece oculto no que se mostra de pronto e, no mais das vezes, mas que é ao mesmo tempo algo que pertence essencialmente ao que se mostra de pronto e no mais das vezes, ao ponto de até constituir seu sentido e fundamento. (HEIDEGGER, 2012, p. 121).

O fato da noção de "fenômeno" ter essa dimensão bipolar (ocultamentodesocultamento) radicada na sua própria natureza faz com que Heidegger justifique a necessidade da fenomenologia, enquanto aquela que tem por missão des-ocultar a constituição do ser do ente na busca pela sua verdade ontológica. Aliado a isso, podemos entrever que Heidegger já anuncia a concretude da tarefa deste método. Em consequência desta análise, podemos afirmar que a Fenomenologia é o instrumento e método que dá acesso ao sentido fenomenológico do fenômeno, e não meramente ao sentido vulgar do mesmo. Assim, o fato de sempre e no mais das vezes no seu processo de mostração o ser se velar e se dissimular no aparecer dos entes vai ao encontro daquilo que é o fenômeno, que o conceito de fenomenologia busca explicitar em sua referência metodológica. Segundo Marlène Zarader:

Se agora nós procuramos determinar o que é visível e o que é dissimulado, é claro que, na problemática heideggeriana, o que se mostra é o ente, ao passo que o que fica todo ocultado acompanha o que se mostra, esse não é o ente, mais seu ser. $\mathrm{O}$ conceito vulgar de fenômeno, esse será, pois, o ente (enquanto ele se mostra), o conceito fenomenológico de fenômeno - quer dizer o tipo de fenômeno que a fenomenologia deve tomar por objeto - esse 
será o ser (enquanto ele pode e deve ser mostrado). (MARLÈNE

ZARADER, 2012, p. 85).

Esse percurso traçado por Heidegger, para esclarecer a extrema relevância dessas determinações do fenômeno em seu modo de se dar é o que a ontologia necessitava para fundamentar a sua problemática. Assim o exercício fenomenológico deixa de ser um puro formalismo e passa a ser uma urgência paradigmática para repensar toda história da metafísica e seu esquecimento do ser. Esse primado da tendência para o encobrimento, embasado na analítica existencial é um elemento que concedem uma unidade interna entre objeto e método como lugar da origem da metodologia fenomenológica heideggerina, com base no pré-entendimento que o Dasein possui do seu ser.

O núcleo do método fenomenológico procura voltar à dimensão do sentido primitivo e fundador que constitui a centralidade de onde se originam as significações derivadas. Assim sendo, nessa tarefa de explicitar o ser que cabe à ontologia no seu exercício fundante, fica claro para Heidegger a impossibilidade de se embasar sobre algum paradigma da história da filosofia. Por isso que para que o ser venha à luz nesta operação de desvelamento, a ontologia ganha um instrumental proporcional ao tamanho desta tarefa:

\begin{abstract}
A fenomenologia é o modo-de-acesso ao que deve ser tornar tema da ontologia por determinação demonstrativa. A ontologia só é possível como fenomenologia. $\mathrm{O}$ conceito fenomenológico de fenômeno designa, como o que se mostra, o ser do ente, seu sentido, suas modificações e derivados. (HEIDEGGER, 2012, p. 123).
\end{abstract}

Heidegger, ao atentar à manifestação do fenômeno e suas várias tendências ao encobrimento, postula que seu método deverá necessariamente levar em conta esse modo de se dar do fenômeno. Com relação a essa abordagem heideggeriana, Marlène Zarader nos adverte:

[...]. Que não se poderá abordar de maneira satisfatória, e elaborar corretamente a questão do sentido do ser, se não se considerar a condição do ente como ele se dá, segundo seus modos de doação. Retornar à coisa mesma, para Heidegger, é se voltar para a doação do ente, a fim de explicitar seu modo de ser. Não há, a seus olhos, nenhuma outra maneira de qualquer coisa de apropriado relativamente ao ser. Mas isso significa que o discurso relativo ao ser (quer dizer a ontologia - mas ontologia bem compreendida) não pode encontrar legitimação senão na descrição escrupulosa do modo cujo ente se dá e aparece. Tal é o sentido da afirmação segundo a qual a ontologia não é possível senão como fenomenologia. (MARLÈNE ZARADER, 2012, p. 79). 
Neste movimento regressivo que procura desentranhar o ser de todos seus encobrimentos em que fora sendo sedimentados progressivamente nas sucessivas tentativas de diversos autores, o filósofo de Freiburg procura nos advertir sobre algumas mudanças no delineamento do seu projeto filosófico. Uma delas é com relação ao modo de manifestação do ser do ente, como ele mesmo nos mostra: “O ser do ente é o que menos pode ser concebido como algo ,atrásee do qual ainda haveria algo que „não aparece ee" (2012, p. 123). O método ora proposto, apesar de buscar uma região ainda inexplorada, não trabalha com o paradigma da postura teórica em que a relação sujeito-objeto opera numa relação de interposição, em que existe uma consciência como ponto de partida absoluta que apreende de forma objetiva qualquer pensamento, ideia ou coisa na sua imparcialidade.

Tomemos guarda aqui o fato de que esse ser não é de modo nenhum o que se esconderia atrás dos fenômenos; ele é o que se dá ao mesmo tempo que os fenômenos, embora ele seja paradoxalmente dissimulado por eles. É esse ser que deve tornar-se fenômeno. E se ele pode se tornar, é que em um sentido ele já o é. (MARLÈNE ZARADER, 2012, p. 85)

A própria maneira do ser se manifestar já traz consigo sua essência intrinsicamente ligada na sua existência (ek-sistência). Por isto, para Heidegger, não há este "atrás" no modo como ele se manifesta. Nesse estabelecimento existencial do Dasein, há a possibilidade de que o seu modo de ser mais próprio não se revele na sua abertura de pronto e no mais das vezes. Assim como o método de Heidegger é um método de explicitar o ser que se dissimula no ente. Nesta tarefa fundamental de desvelar o que se oculta no que se manifesta do fenômeno Heidegger nos alerta que:

\footnotetext{
"Atrás" dos fenômenos da fenomenologia não há essencialmente nada mais, embora seja possível que esteja oculto o que deve tornar-se fenômeno. E precisamente por isso, porque os fenômenos não se dão de pronto e no mais das vezes, é que se exige fenomenologia. O ser-encoberto é o conceito oposto ao de "fenômeno". (HEIDEGGER, 2012, p. 123).
}

Heidegger segue então na sua tarefa de explicitação ontológica via método fenomenológico, alegando que a analítica do ser não pode ser determinada diretamente. Essa tarefa de explicitação do ser é assinalada primordialmente no "ente". Por isso, para que se chegue à manifestação do ser na sua originalidade, é preciso que primeiro se detenha na análise do ente, uma vez que o ser é sempre ser do ente. Como próprio Heidegger nos descreve “[...] ser é cada vez ser de ente e, assim, para que o ser possa ser posto-em-liberdade, é preciso então que o ente ele mesmo se apresente corretamente" (2012, p. 125). Assim, nesse horizonte compreensivo, em que esta 
analítica se coloca para explicitar as estruturas ontológicas do ser, toda tarefa precisa inicialmente passar pela análise do modo de ser desse ente, ou seja, por aquilo que ele tem de mais próprio. Para Heidegger, "a fenomenologia é, portanto, o instrumento e o método que dá acesso, não ao fenômeno no sentido vulgar, mas ao fenômeno no sentido fenomenológico. Este é o que primeiramente e no mais das vezes não se dá como manifesto. A este dirige a fenomenologia". (ERNILDO STEIN, 2001, p.169). É por isso que, desde o início dessa análise existencial, esse autor expõe a necessidade de partir de um ente exemplar para tal exposição. De modo que

\begin{abstract}
O privilégio ontológico do Dasein se revela ao olhar fenomenológico, e se o método fenomenológico se recomenda de início, é em primeiro lugar porque ele corresponde às exigências de aceder ao ser deste ente que nós somos e porque ele coloca em obra o modo de mostração requisitado pelo modo como esse ente vem precisamente ao encontro (COURTINE, 1990, p. 268)
\end{abstract}

Para que se realizasse a tarefa da explicitação do ser na sua dimensão ontológica fundamental pelo viés do método fenomenológico, essa análise necessariamente teria que ser precedida somente a partir do ente, que sendo, já sempre se relaciona compreensivamente com o seu ser. O Dasein é este ente privilegiado e somente a partir dele é que se pode realizar a análise fenomenológica do fenômeno do ser, pois ele realiza seu ser a partir de uma das possiblidades de relação compreensiva com ele mesmo. É assim que para Heidegger, "A tarefa prévia para obter uma segurança „fenomenológica ${ }^{e e}$ do ente exemplar como ponto-de-partida para a analítica propriamente dita já está sempre delineada a partir da meta dessa analítica" (2012, p. 127). A primazia do Dasein, que o diferencia substancialmente dos outros entes, está embasada pelo fato dele se relacionar com ele mesmo numa compreensão ontológica de si.

\title{
1.3 A Ontologia como Fenomenologia Hermenêutica
}

A fenomenologia busca indagar pelo sentido do ser a partir da indagação pelo sentido do ser da existência. No sentido mais profundo, as estruturas do Dasein serão analisadas para que se revele o horizonte para uma ontologia fundamental, ou, mais precisamente, para o sentido do ser em geral. Por isso Ernildo Stein interpreta essa meta de Heidegger no seguinte modo: "Essa (ideia do ser em geral), porém, somente se deixa compreender, originariamente, fundada numa originária interpretação do ser-aí conduzida pela ideia de existência” (2001, p. 254). Então, se a 
fenomenologia é possível como explicitação, é porque existe sempre já no homem um entendimento implícito do ser, que pode ser trazida à luz por um processo adequado de interpretação. Assim como esse autor nos diz, "da investigação ela mesma resultará que o sentido metódico da descrição fenomenológica é interpretação" (2012, p. 127). De acordo com Heidegger, o ser somente pode ser tematizado num saber ontológico, porque o ente ao qual estabelece a relação com ser já de modo assinalado é compreendido antecipadamente e pré-ontologicamente imerso na sua existência fática concreta e na sua historicidade. Para respaldar essa dimensão interpretativa do seu método, Heidegger se embasa no fato de que o pré-entendimento constitui um modo essencial de ser do Dasein. Assim, visto que essa analítica existencial consiste em descrever os modos do ser do Dasein, Heidegger chama essa descrição de um modo particular: "explicitação". Que pode assim ser traduzida por "interpretação". Segundo Otto Pöggeler:

\begin{abstract}
Visto que a fenomenologia hermenêutica busca chegar à indagação pelo sentido de ser a partir da indagação pelo sentido de ser da existência, "o sentido primário" da hermenêutica é o de uma analítica da existencialidade da existência. Porque o sentido de ser daquilo que Husserl entende como eu transcendental é definido por Heidegger como existência efectiva, que em si mesma é hermenêutica; a fenomenologia transcendental de Husserl torna-se em Heidegger em fenomenologia hermenêutica. (OTTO PÖGGELER, 2001, p. 73)
\end{abstract}

Podemos, com isso, descrever que o que caracteriza o existir do Dasein humano é ser uma ek-sistência, uma abertura ao horizonte do ser. Disso depreendemos que o aspecto fundante do logos da fenomenologia do Dasein embasa-se no entender interpretativo "[...] pelo qual se anunciam ao entendimento-do-ser inerente ao Dasein ele mesmo o sentido de ser próprio e as estruturas-fundamentais do seu próprio ser" (2012, p. 127). Se tal ontologia é possível na sua efetividade antipredicativa é porque existe uma pré-ontologia que ainda não foi desvelada ou mesmo conhecida, mas que já é vivida existencialmente. Vemos assim que Heidegger quer partir da vida na sua efetividade exposta, na sua concatenação com mundo. Por isso, o homem parte de um pré-entendimento, em que sua existência já sempre é entendida de alguma forma, uma vez que esse (Dasein) está imerso no seu existir lançado em-o-mundo.

Heidegger usa o método hermenêutico no sentido que o próprio Dasein imerso na sua cotidianidade se auto-interpreta numa tarefa filosófica que lhe é própria. Não queremos dizer com isso que essa interpretação sempre se efetua numa dimensão 
autêntica, mas ele pode no mais das vezes se interpretar pelas orientações dos ditames impessoais que ele sempre recebe do seu mundo circundante. Ernildo Stein acredita que "as estruturas desse ente serão analisadas para que desvelem o horizonte em que se afirma a questão do sentido do ser em geral. É na análise do ser-aí que a fenomenologia assume uma dimensão hermenêutica, explicitadora” (2001, p. 171).

A modalidade que Heidegger trabalha no conceito de hermenêutica se dá “[...] na medida em que o Dasein tem precedência ontológica em relação a todo ente” (2012, p.127). Assim, essa prioridade que o Dasein tem depende da sua possibilidade de existência que, ao interpretá-la primariamente, o faz necessariamente buscando primeiro a existenciariedade da existência. Heidegger, ao estabelecer esse ponto de partida adequado à interpretação do sentido do ser, vislumbra o quanto esse sentido primário pelo primado da existenciariedade se torna no seu método filosoficamente primordial. Pois, como a existência humana existe já exposta ao ser, o método parte da hermenêutica para revelar o ser desse ente, uma vez que todo questionamento filosófico se inicia com a existência e na sua circularidade para ela retorna. Vinculado a isso, Heidegger nos mostra que, em sentido derivado, a hermenêutica do Dasein prepara ontologicamente a historicidade, "[...] isto é: a metodologia das ciências de conhecimento-histórico do espírito" (2012, p. 129). Assim, ao estabelecer que o Dasein é a condição ôntico-ontológico da sua démarche fenomenológica, vemos que Heidegger tem uma preocupação com a necessidade de estabelecer como ponto de partida fundamental a interpretação do sentido do ser em geral. Ora, já que o Dasein é histórico, seu questionamento sobre o ser também não escapa dessa dimensão inerente a ele. Desse modo, esse sentido do ser que esse filósofo busca desvelar somente pode ser anunciado ao homem no horizonte do tempo, que é "onde" em sentido derivado da hermenêutica pode se explorar a história sobre a indagação acerca do ser.

Heidegger, para coroar a exposição provisória da fenomenologia, nos “[...] mostra como é possível que o ser enquanto „o transcendens por excelência ${ }^{e e}$, pode, contudo, e deve mesmo ser problematizado a partir do ser-aí.” (ERNILDO STEIN, 2001, p. 171). Só que esse autor ao usar esse conceito transcendere derivado do latim não quer com isso retomar a ideia platônica com toda sua alusão metafísica. Heidegger vai buscar superar esses preconceitos que ressoaram pela tradição ao explicitar a relação que a transcendência tem com sua hermenêutica fenomenológica. Nessa perspectiva, transcendência é ultrapassamento, "um além de..." para um deslocamento, de modo que ultrapassar é ir além da existência, ir além do próprio modo de ser. “ $\mathrm{O}$ 
conhecimento transcendental entendido hermeneuticamente é indagação pelo sentido de ser da existência e pelo sentido de ser, e consequentemente "ontológico", abertura do ser" (OTTO PÖLLEGER, 2001, p. 73).

Desse modo, transcendência no sentido que Heidegger indica para esse ente privilegiado a quem compete o entendimento do ser, é uma característica própria do Dasein, uma vez que ele já se encontra sempre aberto aos entes em toda compreensão antipredicativa. "Ser é o trancendens pura e simplesmente. A transcendência do ser do Dasein é uma assinalada transcendência na medida em que nela residem a possibilidade e a necessidade da mais radical individualização". (2012, p. 129) Para Heidegger, essa transcendência do Dasein deve ser buscada na superação do ente em direção ao ser. Somente assim é que se pode elevar ao ser, isto é, passando pela necessidade de interpretar um ente assinalado que de pronto e no mais das vezes se encontra aberto e exposto ao ser. Relacionado a isso, a máxima individualização do Dasein se embasa no fato dele ser o único ente capaz de se relacionar com seu ser elemesmo, diferentemente de um cavalo, de uma porção de terra, que é só um ente, o Dasein é um ente que entende seu ser, isto é, ele é o único ente capaz de perguntar o que ente é. Ele é o único que pode maravilhar-se com que o ente seja, até mesmo seu ser, essa pré-compreensão que caracteriza seu ser e o define é que lhe dá condições dele ser o que ele é .

O conhecimento transcendental desta abertura, enquanto presença $e k$ statica à revelação do ser, não se opera ao modo medieval ou mesmo aristotélico que, ao postular o ser como um transcendens, deixa obscura a diferença entre ser e ente. A renovação da questão do ser proposta por Heidegger se baseia na indagação elementar pelo ser que parte da existência efetiva e essencialmente temporal. Foi preciso, então, que Heidegger se orientasse pela condução a partir desse ente específico, para que de certa forma este ente privilegiado pudesse ser como que um ponto de confluência entre a hermenêutica da facticidade possibilitada como ser que ek-siste, e que está sempre previamente aberto ao ser e sua explicitação, e uma ontologia fundamental pela transcendência do ente que entende o ser. Vale ressaltar que esse conhecimento transcendental não acontece num plano do eu transcendental, em que fenômeno é um dado da consciência obtido pela redução eidética. Segundo Pöggeler: 
descolorida realização. Quando Husserl objectou a Heidegger que a própria "efectividade" é um eidos, então deve se recusar-se o pressuposto aí contido de que cada "essência" ou "ser" seja eidos. Em Ser e Tempo, Heidegger funda a "visão essencial" no compreender da existência efectiva. (OTTO PÖGGELER, 2001, p. 76)

Constatamos que a crítica desse autor se radicaliza ao tomar este "eu transcendental" husserliano não numa dimensão da consciência. Em Heidegger, ele é posto na sua condição de existência efetiva lançada em-o-mundo e entendida na sua plena temporalidade. Desse modo é que se pode afirmar que o conhecimento transcendental se individualiza no ser do Dasein, porque somente este ente pode indagar pelo sentido do ser e da existência ontologicamente, uma vez que a ele compete esse pré-entendimento (não teórico) de um conhecimento transcendental entendido hermeneuticamente.

Heidegger estabelece uma conexão entre a existência (ser para fora) e verdade. Essa conexão primordial encontra-se no que o ente (Dasein) é na verdade (abertura). Courtine entende essa relação da seguinte forma:

\begin{abstract}
„O Dasein está na verdade“ medida em que o ser-aí é essencialmente abertura e que enquanto aberto ele abre e descobre, ele é essencialmente „verdade". Mas ser na verdade para ser-aí, isto significa também e essencialmente ser ,na verdade da existência. (COURTINE, 1990, p. 273).
\end{abstract}

A articulação que Heidegger pensa na elaboração do conceito de verdade, enquanto veritas transcendentalis, ou mais precisamente como desvelamento daquilo que se dissimula no ente, está intimamente ligada à noção de fenomenologia justamente "por fazer ver a partir dela mesmo o que se mostra como tal como ele por si mesmo se mostra”. Assim é neste sentido que, com esta tarefa de desvendar o que se dissimula no ente, a fenomenologia está intimamente ligada à reinterpretação de Heidegger com relação ao conceito de verdade. "A fenomenologia hermenêutica funda, portanto, a veritas transcendentalis, o horizonte de abertura no ser-aí concreto que permite a interrogação pelo sentido, pela verdade o ser em si mesmo". (ERNILDO STEIN, 2001, p. 173). Ao primar por esta definição de que a fenomenologia hermenêutica deve pautar não pelo ente que se impõe, mas por aquilo que é dissimulado e encoberto (o ser do ente e o sentido do ser) a fenomenologia enquanto interpretação é ontologia como uma explicitação do ser do ente e do seu sentido. $\mathrm{O}$ emprego deste conceito original de fenomenologia articulado com uma ontologia do 
entendimento fundamentados na hermenêutica da factualidade do homem leva Heidegger a delinear que:

\begin{abstract}
Ontologia e fenomenologia não são duas disciplinas diversas que, ao lado de outras, pertencem à filosofia. Ambos os termos caracterizam a filosofia ela mesma, segundo o objeto e segundo o modo-de-tratamento. Filosofia é ontologia fenomenológica universal cujo ponto de partida é a hermenêutica do Dasein, a qual, como analítica da existência, fixou a ponta do fiocondutor de todo perguntar filosófico lá de onde ele surge e para onde ele retorna. (HEIDEGGER, 2012, p. 129).
\end{abstract}

A fenomenologia não pode ser entendida como uma disciplina ao lado das outras disciplinas filosóficas com seus objetos circunscritos precisamente erigida em um sistema fechado. A fenomenologia dever ser concebida no universo de possibilidades que lhe cabe como uma busca do entendimento. Desse modo, não se pode reduzi-la a um código de prescrições irredutíveis, nem mesmo com um movimento filosófico como fora o existencialismo francês. Com este viés que possibilita inspirações diversas, a fenomenologia assume uma perspectiva riquíssima por abrir o horizonte para sua universalidade, sobretudo ao assumir uma visão tão lata que no seu alcance abarca e envolve toda temática central da filosofia, que não é outra coisa senão o pensamento do ser.

A fenomenologia como retorno à ontologia é uma destinação para si mesmo, enquanto a ontologia é designação do conteúdo. Com estas bases estabelecidas (fenomenologia hermenêutico-existencial do Dasein), a filosofia, se pudermos assim resumir, é ontologia fenomenológica universal, que trata da hermenêutica da existência, pois a pergunta pelo ser está presente com pergunta inerente ao viver do homem em todo gesto de existir. Essa ek-sistência entendida no seu manifestar concreto repele qualquer análise abstrata da transcendência, de modo que no acontecer fático permite a Heidegger recuperar o sentido primitivo e velado nos entes, isto é, o sentido do ser. Portanto, pela analítica do Dasein embasada na sua situação ôntico-ontológica, faz com que Heidegger adentre no manifestar fático da transcendência do Dasein, e a partir daí ele possa determinar a transcendência do ser como eclosão deste ente privilegiado.

Heidegger ao esboçar estes traços fundamentais da conversão da fenomenologia em ontologia fundada numa hermenêutica da existência, se embasava na máxima de seu mestre Husserl: "às coisas elas mesmas". Contudo, a noção de reinterpretação que ele opera de conceitos da tradição consubstanciais (fenômeno, logos, aletheia, etc.) a sua proposta de metodologia filosófica, conjuntamente com a 
necessidade de recuperar uma noção originária de mundo e da existência pela tarefa da destruição, resultaram num distanciamento das noções básicas das teses husserlianas. Assim, ao romper com esta linha continuísta do seu mestre Husserl de posse de um novo conceito de fenomenologia hermenêutica, ao qual este se torna indiferente ao conteúdos-de-coisa com que ela se ocupa, esse autor quer evitar que seu método seja um modelo hermeticamente fechado e reduzido a um código inalienável, mas como ele mesmo afirma: "Acima da realidade está a possibilidade. Entender a fenomenologia consiste em apreendê-la unicamente como possibilidade". (2012, p. 129-131). Assim, entendê-la na sua possibilidade não é circunscrevê-la em um "ponto de vista" ou uma corrente de pensamento, pois o ser não se esgota numa possibilidade filosófica, mas é entendê-la no seu foco propiciador de uma miríade de inspirações diversas propiciadas pela abertura do horizonte que este método traz consigo.

\footnotetext{
Se o Dasein é sua abertura, se a revelação lhe pertence constitucionalmente. [...] ser é verdade que o projeto é sempre abertura-em-projeto. [...]. O ser na verdade se encontra por aí exposto de imediato a alternativa da autenticidade e da inautencidade. Na abertura autêntica, ,o Dasein pode se abrir a ele-mesmo em e como seu poder-ser o mais próprio “. E é precisamente essa abertura autêntica que „manifesta o fenômeno da verdade a mais originária sobre o modo da autenticidade". (COURTINE, 1990, p. 273)
}

O homem ao viver transcendentalmente na sua imanência, ele lançado a sua factualidade e se entende retrospectivamente como homem que pode ser preenchido por esta ou aquela possibilidade de ser e, por isso, se identifica como acolhedor apaixonado das possibilidades de ser pelos entes que o tocam ou não, o convocam ou não. Somente assim ele pode permitir que novas possibilidades do ser desabrochem. Desse modo, a ontologia não se constitui em Heidegger como um recenseamento substancial dos entes (os entes são isto ou aquilo), mas a ontologia vai correlativamente ao caráter temporal de quem interroga por ela e, deste modo, ela vai se constituir como uma interrogação aberta, definida, mas nunca acabada a respeito do ser dos entes, mesmo porque, apesar do homem pastorear o ser, este não se deixa enclausurar nos domínios da condição humana, mas a transcende rumo a seu horizonte mais próprio.

\subsection{Considerações finais}

Detemo-nos nessa dinâmica da relação entre os conceitos pontuados por Heidegger, nesse $\S 7$ de Ser e Tempo, para mostrar a ausência de uma reposta 
adequada à indagação sobre o sentido do ser, urge re-pensar essa nova via de acesso a ontologia. Assim, se a fenomenologia é possível como explicitação, é porque existe sempre já no homem uma compreensão implícita do ser que pode ser trazida à luz por um processo adequado de interpretação. Assim como o Dasein estabelece a relação com ser, já de modo assinalado este é compreendido antecipada e préontologicamente. Observamos que o que caracteriza o existir do Dasein humano é ser um ek-sistência, uma abertura ao horizonte do ser. Disto depreendemos que o aspecto fundante do logos da fenomenologia do Dasein funda-se no compreender interpretativo. Heidegger usa o método hermenêutico no sentido que o próprio Dasein imerso na sua cotidianidade (hermenêutica da facticidade) "[...] é, em si mesmo, hermenêutico, enquanto já sempre se movimenta numa compreensão de seu próprio ser”. (ERNILDO STEIN, 2001, p.188). Outro conceito que emerge da concepção do método fenomenológico heideggeriano é a noção de transcendência, que ele trabalha em relação à analítica existencial do ser do ente (Dasein). Segundo Heidegger o "Ser é um transcendens pura e simplesmente". Consideramos assim que esta transcendência do Dasein deve ser buscada na superação do ente em direção ao ser. Somente assim é que se poderá ascender ao ser, isto é, passando pela necessidade de interpretar um ente assinalado que de pronto e no mais das vezes se encontra aberto e exposto ao ser.

Por fim procuramos estabelecer que o conceito de verdade exposto por Heidegger, enquanto veritas transcendentalis, ou mais precisamente como desvelamento daquilo que se dissimula no ente, está intimamente ligada à noção de fenomenologia. Justamente essa noção trabalhada por Heidegger: "por fazer ver a partir dela mesmo o que se mostra como tal como ele por si mesmo se mostra". A fenomenologia hermenêutica pauta-se não pelo ente que se impõe, mas por aquilo que é dissimulado e encoberto (o ser do ente e o sentido do ser). A fenomenologia enquanto interpretação é ontologia como uma explicitação do ser do ente e do seu sentido. Isso está vinculado à noção de Alétheia como des-velamento do que está dissimulado no ente. Desse modo, da alétheia advém, sobretudo, a dimensão ambivalente da fenomenologia enquanto ela deve desvelar aquilo que a partir de si sempre se oculta e se vela nos entes. (ERNILDO STEIN, 2001, p. 181)

Finalmente procuramos ressaltar que a fenomenologia dever ser concebida dentro do universo de possibilidades que lhe cabe como uma busca de entendimento, ou mais precisamente como uma "ontologia da compreensão" como bem define Ernildo Stein. Deste modo, não se pode reduzi-la a um código de prescrições 
irredutíveis. Procuramos ressaltar que esse viés que possibilita inspirações diversas à fenomenologia assume uma perspectiva riquíssima por abrir o horizonte para sua universalidade, sobretudo ao assumir uma visão tão lata que no seu alcance deseja abarcar e envolver toda temática central da filosofia, que não é outra coisa senão o pensamento do ser.

\section{Referências}

ABBAGNANO, Nicola. Dicionário de Filosofia. Tradução: $1^{\circ}$ edição brasileira coordenada e revisada por Alfredo Bosi, revisão da tradução e tradução dos novos textos Ivone Castilho Beneditti. 4 ed. São Paulo: Martins Fontes, 2000.

CASANOVA, M. A. Compreender Heidegger. Petrópolis: Vozes, 2009.

COURTINE, Jean-François. Heidegger et la Phénoménologie. Paris: Librairie Philosophique J. Vrin 6, place de la Sorbonne, 1990.

HEIDEGGER, M. Ser e Tempo. Trad: Fausto Castilho. Campinas, SP: Editora da Unicamp, RJ: Vozes, 2012.

HUSSERL, E. A Ideia da Fenomenologia. Lisboa: Edições 70, 1990.

INWOOD, M. J. Dicionário Heidegger. Trad: Luísa Buarque de Holanda, Revisão: Márcia Sá Cavalcante Shuback. Ed. J. Zahar, 2002.

MACDOWELL, João Augusto A. Amazonas. A gênese de ontologia fundamental de Martin Heidegger: ensaio e caracterização d o modo de pensar de Sein und Zeit. São Paulo: Loyola, 1993.

PÖGGELER, O. A via do Pensamento de Martin Heidegger. Tradução: Jorge Telles de Menezes. Lisboa: Instituto Piaget, 2001.

STEIN, ERNILDO. Compreensão e Finitude: Estrutura e movimento da interrogação heideggeriana. Ijuí, Rio Grande do Sul: Ed. Unijuí, 2001.

Seis estudos sobre "Ser e Tempo": Petrópolis, RJ: ed. Vozes, 1988.

ZARADER, Marlène. Lire Être et Temps de Heidegger: Um commentaire de la première section. Paris: Librairie philosophique J. Vrin 6, place de la Sorbonne, 2012. https://doi.org/10.3917/cite.052.0152

Heidegger e as palavras da origem: Trad: João Duarte. Lisboa: Instituto Piaget, 1990. 
Revista Primordium v.3 n.6 jul./dez. - .2018 ISSN: 2526-2106

http://www.seer.ufu.br/index.php/primordium

Data de aceite: $25 / 02 / 2019$ 